\title{
Never Normal
}

Normal never was. And yet it is the framing that structures our imaginationsintellectual, ideological, political, aesthetic, and otherwise-in so many situations. At the time of this writing, and certainly by the time this issue reaches you, the more privileged sectors of our world are in the process of narrating a "return to normal." As people with various kinds of social advantage access the COVID vaccine and scientists predict newly acceptable modes of gathering for work and recreation, things that have been put on hold for months are becoming possibilities once again. Working in the office rather than at home, attending live performances rather than streaming them, holding in-person rather than virtual get-togethers, and in-person rather than remote teaching and learning are-for some-among the most anticipated returns to what was taken for granted as normal at the beginning of last year. And yet, we are learning that the pandemic has reshaped our world in lasting ways, and some of our social norms will not be resumed with unquestioned ease. The broader use of technologies that improve access for all (e.g., opportunities for virtual presence, the use of captioning, producing information in multiple media) has in many instances lessened the individualized burdens typically placed on people with disabilities to generate the affordances necessary for their participation in work and social environments; and now that these affordances have been incorporated into many institutions' infrastructures (operationally and financially), we cannot return to normalizing a lack of access to them for those who need it. As labor shortages across the United States are demonstrating, many workers refuse to return to a normal that requires them to work for less than a living wage or return to workplaces that normalize harm in the form of microaggressions and harassment against which telecommuting forms a buffer. Yet other workers still cannot return to former working conditions while they lack access to robust resources that help them honor their personal commitments (including many forms of caregiving).

Therefore, "postpandemic" remains an infelicitous utterance for now. Postshutdown, in ableist terms, may be true, as those with robust immune systems, access to vaccines, and/or a resolute sense of faith/fate are able to resume moving confidently through the world in ways that approximate pre-COVID times. However, even in well-resourced societies, many people's health and safety depend on continuing to limit their presence in public as newer virus variants circulate and create regional spikes in confirmed cases, and a third wave of widespread infection and death is currently inflicting more damage throughout the Global South. Like other fraught "posts," aspirations to define a postpandemic status quo demand a rigorous attention to the recent past, one that places that past in proper relationship to a longer history. We cannot treat the past eighteen months as a void, suturing the gap between pre- and postpandemic with historical erasure. The contents of this 
issue affirm the ongoing value of documenting and carefully analyzing moments of disruption that call the status quo into question, enacting alternative possibilities for the present and future. Across a range of sites, the authors in this issue grapple with the ways that social actors' disputations of the normal can have ripple effects that expose the provisionality of what we are conditioned to take for granted as the way things must be.

The issue begins with Ineke Murakami's assessment of the short-lived Digger movement in seventeenth-century England, focusing on the spring and summer of 1649, when Gerrard Winstanley and his associates rejected the norms of the Sabbath and began to work the barren soil of George Hill, preparing it for plowing. Their action not only rejected the religious and cultural norms of protecting the Sabbath as a day of rest, but also rejected political norms that structured property relations and social hierarchies in ways that stigmatized the poor and their labor. Therefore, rather than ceding this historical episode, in which Winstanley and others were attacked by townspeople fearful and resentful of the Diggers' populist politics, to scholars of religious and political history, Murakami encourages performance scholars to help explicate the significance of what she considers an "ideal case study" of extraordinary politics in action. Her interdisciplinary analysis deploys theories of collective performance and affect theory, merging them with existing scholarship on the Diggers to offer a more nuanced analysis of the ways that a community with fewer than fifty members could have an outsized impact upon national political discourse of the time and for decades to come.

Addressing a very different social context, Vivek Narayan's essay on caste identity in colonial Kerala brings together rich archival materials with the theories of widely known Anglophone performance theorists, as he suggests that the best way to understand the regulation of caste is as performance that permeates costume, gestural vocabulary, linguistic conventions, and more. He centers his analysis on a moment of disruption of these social norms, the villuvandi samaram, or bullock cart strike, of 1893, where Ayyankali, a member of an untouchable caste, wears the clothes, occupies the public space, and adopts the social mannerisms of the elite caste, contributing to the revolution against social hierarchies that were deeply embedded in the Indian colonial project. As Narayan argues, Ayyankali's protest "enacted claims to equality that reimagined conceptions of life and what it meant to be human. . . [making available] new forms of personhood based on what we have come to recognize as modern values: respect, autonomy, inwardness, and a sense of self-possession." By articulating the relationship between caste codes (rules governing behavior) and caste scripts (the practices through which these codes were enacted in social relations), this study both pinpoints a watershed moment in Kerala's colonial history and offers a methodological tool that has applications for the study of performed sociopolitical inequality across historical sites.

The third essay, by Tarryn Chun, begins the issue's pivot toward the present, and the various ways that artists and scholars are responding to the demands of a once-in-a-generation cultural moment. Chun focuses on Wang Chong's role as artistic director of the Beijing-based theatre company Théâtre du Rêve Expérimental (Xinchaun shiyan jutuan) and documents his work in the first half of 2020 as among the earliest efforts of theatre practitioners to adapt their theatre practice rapidly to the circumstances of the pandemic. Placing those pandemic- 
mandated adjustments within a longer genealogy of experimentation, Chun characterizes Wang Chong's work as a "theatre of immediacy" that has connections to but also exceeds what has already been defined as intermedial theater in its emphasis on the crisis of intimacy across multiple scales that has become a defining feature of twenty-first-century existence. Presciently, it is Wang Chong's early 2020 production of Waiting for Godot that adapts to pandemic requirements and inaugurates the shift toward a fully virtual rather than intermedial performance aesthetic, representing the relational precarity that so many of us have experienced for the past year and a half. Furthermore, video technology may offer the seductive fiction of placelessness, the sense that we can transcend the limitations of location, but Chun makes clear that Théâtre du Rêve Expérimental's work is absolutely rooted in its materially and politically Chinese contexts even as it attempts to extend beyond them: she argues that one of Wang Chong's important contributions is the reconfiguration of immediacy as politically engaged intimacy, a formulation that is instructive as we "emerge from pandemic temporality to a "new normal." What intimate political engagements will shape our futures within and beyond spaces of performance?

The issue concludes with a special section, "Notes from the Field: Remembering Times of Crisis," which contributes to collective efforts to archive our present moment, especially within the world of higher education. Whether as graduate student researchers, practitioners, educators, activists, or administrators, our contributors share the ways that the COVID crisis affected their spheres of participation in performance. Some of our colleagues have contracted and thankfully survived the virus; others have had to support students and/or colleagues through unfathomable losses. Some institutional aspirations have been placed on pause; others have been reimagined and achieved successes that would have been impossible under standard operating procedures. Students and colleagues have been sources of incredible support and causes for incredible dismay. In addition, performance has offered a vocabulary and/or a set of tactics that allowed people to work for social transformation across areas of the public sphere. Taken together, these reflections document our field's persistence, adaptability, resilience, and righteous concern not just with spaces of education and performance but with the world at large. No, normal never was, but practitioners and scholars of performance and performance history possess unique tools with which to question the forces that produce what Rosemarie Garland Thomson termed the "normate," in both its corporeal and ideological dimensions, in sickness and in health, and through that questioning to expand our imaginations-intellectual, ideological, political, aesthetic, and otherwise.

Cite this article: "Never Normal," Theatre Survey 62.3 (2021): 245-247. https://doi.org/10.1017/ S0040557421000399. 